\title{
Impact of Economic Sustainability in Apparel Factories on Economic Challenges in Saudi Arabia
}

\author{
Sarah Eid Hamalos Aldaadi \\ Fashion and Textiles Dept., King Abdulaziz University, Jeddah, KSA \\ Email: saldaadi0005@stu.kau.edu.sa
}

How to cite this paper: Aldaadi, S. E. H. (2021). Impact of Economic Sustainability in Apparel Factories on Economic Challenges in Saudi Arabia. Open Journal of Social Sciences, 9, 257-272.

https://doi.org/10.4236/jss.2021.97018

Received: June 4, 2021

Accepted: July 18, 2021

Published: July 21, 2021

Copyright $\odot 2021$ by author(s) and Scientific Research Publishing Inc. This work is licensed under the Creative Commons Attribution International License (CC BY 4.0).

http://creativecommons.org/licenses/by/4.0/

\begin{abstract}
The global apparel industry has resisted challenges over the past decade, the garment industry in the Kingdom of Saudi Arabia also faced many challenges at the local and international level. The implementation of the rules and regulations of the World Trade Organization (WTO) and the Kingdom's Vision 2030 has received special attention and economic sustainability has become one of the main objectives of garment factories. The study uses the interview in data collection and the descriptive approach in the qualitative analysis of the data. The impact of economic sustainability on the economic challenges facing (10) small and medium garment factories has been studied with the aim to identify the challenges and economic factors that affect the business strategy and feasibility of implementing economic sustainability. It was concluded that some of the economic challenges are represented in the high operating cost caused by the application of new taxes, including the value-added $\operatorname{tax}$ (VAT), imposition of fees on non-Saudi workers and the updated rules and regulations of the Ministry of Commerce. As such, it was concluded that the economic sustainability component represented in production efficiency, reducing operating costs through modern manufacturing techniques, and reducing supply costs, was a key solution to ensure the survival and sustainability of factories. The study recommended the necessity of implementing industrial cooperation with factories and related companies and preparing a strategic plan to attract investors.
\end{abstract}

\section{Keywords}

Economic Sustainability, Challenges, Apparel Industry, Saudi Economy

\section{Introduction}

The Kingdom of Saudi Arabia is one of the richest countries in the world, as well 
as an economic power, with a large share of global oil resources (Alakkad, 2018). The Kingdom has a clear impact on the local and global markets, and its accession to the World Trade Organization (WTO) in (2005), reflected positively in economic terms, and with the new leadership trying to implement a series of economic reform programs, which includes the Vision 2030 plan, and the National Transformation Program to prosper economically, in light of this, statistics indicate that more than $90 \%$ of the industrial establishments in the Kingdom are small and medium enterprises, which is enough to indicate their economic significance to achieve the goals of economic growth (Al-Mutawa, 2014).

In order to support the local economy, industrial cities and areas of economic activity were built in small and medium-sized cities, because economic transformations and changes occur under the influence of the development of industrial areas (Blachut, 2019). The dynamic link between exports and economic growth in the Kingdom has been studied, because it provides foreign exchange for any country and accelerates its growth, development and sustainability of its economic capacity (Alkhateeb, Mahmood, \& Sultan, 2016).

Hence comes the role of government and private establishments in providing the necessary support early, to face challenges in the Kingdom of Saudi Arabia, in particular, challenges facing the industrial establishments in different sectors (Alkhaldi, Cleeve, \& Brander-Brown, 2018).

The private sector faces economic challenges due to economic fluctuations and new laws. Among these sectors is the apparel industry. The concept of sustainable development (be it environmental, social and economic) has been applied globally in industrial establishments to face such challenges, and economic sustainability can be applied in apparel factories, by reducing operating costs to a minimum and improving workforce productivity, in addition to investing in training human resources, diversifying the capital and attracting investors (Masocha \& Fatoki, 2018). The aspects of the study problem have emerged in the field of apparel industry, which is a non-oil source of income that faces economic challenges leading to bankruptcy and loss of viability and sustainability.

\section{Problem of the Study}

Statistics of the year 2018 have revealed a reduction and closure of some small and medium-sized apparel factories compared to statistics of previous year 2017, as 32 factories were brought to a halt in different regions of the Kingdom (General Authority for Statistics, 2018). In light of this, it is possible to study the impact of economic sustainability on economic challenges facing a sample of apparel factories, to ensure their continuity in the presence of economic fluctuations. Many academics have indicated that small and medium enterprises face challenges in understanding and practicing sustainability (Masocha \& Fatoki, 2018).

Based on above problem, the study's questions were formulated as follows:

1) What are the challenges facing the sample of apparel factories in this study 
as a result of the new industrial and commercial regulations and laws?

2) What is the impact of the Kingdom's current economic climate on strategies of apparel factories from the point of view of factory managers?

3) To what extent can a sample of small and medium apparel factories apply the concept of economic sustainability?

\section{Objectives of the Study}

1) Identifying the similarities between the economic challenges in a sample of small and medium-sized apparel factories.

2) Disclosing the link between strategic solutions in apparel factories and economic sustainability.

3) Identifying the elements of economic sustainability that are applied in the sample apparel factories.

\section{Significance of the Study}

This study aims to promote the apparel industry as a non-oil source of income by spreading the concept of economic sustainability, in an attempt to achieve part of the Kingdom's vision (2030); "a prosperous economy", and highlight the strategy applied by a sample of apparel factories in the Kingdom of Saudi Arabia when facing economic challenges.

It also aims to enrich literature on issues of economic challenges facing entrepreneurs.

\section{Terminology of Study}

Sustainability: A situation in which human activity is conducted in a way that conserves the functions of the earth's ecosystems (ISO 15392, 2008), a transformation of human lifestyle that optimizes the likelihood that living conditions will continuously support security, well-being, and health, particularly by maintaining the supply of non-replaceable goods and services (Geissdoerfer, Savaget, Bocken, \& Hultink, 2017).

Procedural definition: Support and improve the work of apparel factories and its ability to adapt to changes and continue their production.

Economic Sustainability is one of the dimensions of sustainability development and depends on economic considerations in terms of productive efficiency, survival in the market, and saving money (Masocha \& Fatoki, 2018).

Procedural definition: Achieving sustainability in terms of productive efficiency in training employees, reducing operating and supply costs, implementing a financial plan that meets financial obligations and investment plan, and the ability to stay in the market despite economic fluctuations.

Apparel factories: The apparel industry is the transformation of raw materials and supplements through certain designs into apparel, to promote long-term development associated with industrial development, and diversify exports as they are linked to other sectors (Pickles et al., 2015). 
Procedural definition: The study includes small and medium apparel factories that meet the consumer's need for uniform and daily wear for men and women and depend on human and material resources and operate within the Kingdom.

Economic challenges: The economic difficulties are represented in the lack of general economic diversification of the establishment, weak work and investment environment, the imposition of taxes, as well as import and export customs duties.

Procedural definition: Shedding light on the economic challenges facing a sample of apparel factory managers, from their point of view, as a result of the new industrial and commercial laws and the general economic climate in the Kingdom of Saudi Arabia.

\section{Methodology}

The study follows the descriptive approach in analyzing qualitative data from acoustic opinion and comments of the study sample to link together the views. and extract outputs from the study's results and conclusions (Bryman, 2016). It also applies the survey approach; a type of the descriptive approach, which collects data to study the problem within the sample environment (Waked, 2016).

\section{Sampling}

The sample of this research is representative of the research interest group. The nature of the research has an impact on the sample size. For exploratory research designs, such as those using qualitative research, the sample size is typically small.

The study sample is a purposive one, representing small and medium apparel factories. It has the characteristics and specifications of the study community, from which the data were collected within study steps (Cooper \& Schindler, 2014). 24 managers of small and medium clothing factories in different cities of the western region were called (via telephone) for an interview. However, 10 out of 24 agreed to participate.

Sampling techniques may be broadly classified as nonprobability and probability. Nonprobability sampling relies on the personal judgment of the researcher rather than chance to select sample elements.

According to Cooper and Schindler (2014), non-probability samples often give acceptable results. Therefore, the current study relied on non-probability sampling.

\section{Tools of Study}

The current study relied on structured personal interviews of the study sample (Brinkmann \& Kvale, 2018). The Alpha Cronbach coefficient was used to measure the reliability of the study tool (Nunnally \& Bernstein, 1994). Arbitration form for the study's tool, (Virla, 2010), and sample's evaluation form on the 
study's tool were used.

\section{Theoretical Framework}

The objective of the theoretical framework was to define the theoretical basis for the study and build on previous literature, to highlight the potential to reduce risks and meet economic challenges through economic sustainability. The main reasons of economic difficulties facing apparel factories are the commercial laws developed following the Kingdom's accession to the Economic Trade Organization, and the implementation of the vision (2030) and its consequences, indicating the existence of economic obstacles, financial requirements and significant tax obligations.

The economy of the Kingdom of Saudi Arabia and the Kingdom's strategic geographical location which links two continents were also discussed. It was maintained that the Kingdom is doing its best to develop itself despite the economic challenges it faces.

The Saudi economy applies the same development approach followed by the developed countries. In this part, the main government bodies, which are directly related to the Saudi economy, were explored to link together some points related to the economy. The great challenge emerged as diversifying the Saudi economy away from dependence on oil, and working on preparing the economy towards achieving global commitment, given the fact that the Kingdom is a member of the World Trade Organization.

The theoretical aspect also addressed the study of sustainable development and its principles as outlined in previous literature. Three main themes were explored: the economic challenges facing Saudi Arabia following its accession to WTO; the development and challenges facing SMEs; sustainable development; the importance and elements of economic sustainability; and the theory of economic sustainability. The theoretical framework was linked to the applied framework in order to determine the study methodology through economic theory, sample design, study tool and procedural processes.

\section{Study Procedures}

The current study relied on personal interviews to collect answers from a sample of apparel factory managers through a set of open questions covering the study's axes.

The interview questions covered three main areas related to Saudi small and medium-sized apparel factories as follows: 1) sustainability, through achieving elements of economic sustainability, 2) economic obstacles and challenges facing apparel factories, and 3) the strategy that factories follow to overcome these challenges, and its role in fostering economic sustainability. The duration of each interview ranges between (60 to 90) minutes.

Before starting to ask questions, a demographic information form comprised of some questions related to the sample was presented to participants. It in- 
cluded information on: 1) age; 2) years of work in the factory; 3 ) academic qualification; 4) Job title. This form was meant to facilitate the course of the personal interview, and focus on its topics.

To collect data effectively through interviews, the research procedures followed the following stages: 1) development of a study tool; 2) validating the study tool; 3) Procedures of the study tool.

\subsection{The Validity and Reliability of the Study Tool}

\subsubsection{Validity Scale}

The validity of the tool was measured through apparent validity. The questions of personal interview were based on the following:

1) The questions were reviewed by a group of three experts in the field of study to ensure their accuracy, arbitrate the link between the questions and the axes of the study, and to reformulate some of the questions because they were unclear or caused confusion. The amendment was made based on arbitrators' recommendations. The percentages of agreement between the arbitrators ranged between (80\% - 95\%). The overall average agreement percentage reached (86\%).

Based on a Virla's study (2010), (Table 1) indicates that the study tool has received a high degree of validity.

2) Testing the questions that aim to collect qualitative data before start of interview, according to a Litwin's study, and verifying the method of data collection and the form and formulation of the questions, based on the advice of Mora study in 2011.

Four key concepts were studied to validate the questions including 1) the validity of questions' axes: as the questions must appear in the correct way to obtain the information necessary for the research; 2) the validity of the content: to ensuring that the interview questions reflect the basic topic of the research; 3) internal validity, as the questions must determine the relationship between the first axis of economic sustainability, and the second axis of economic challenges; and 4) external validity which focuses on the possibility of generalizing the result to the sample of apparel factories in this study.

\subsubsection{Reliability Scale}

To measure the tool's reliability, five different answers were placed in front of each question in the personal interview as follows (fully realized, partially realized, I don't know, partially unrealized, not fully realized). In return, the

Table 1. Arbitration results of personal interview questions.

\begin{tabular}{ccccc}
\hline Result's items & $\begin{array}{c}\text { Clarity of } \\
\text { questions }\end{array}$ & $\begin{array}{c}\text { Sequencing of } \\
\text { questions } \\
\text { according to } \\
\text { the study axes }\end{array}$ & $\begin{array}{c}\text { Number of } \\
\text { questions }\end{array}$ & $\begin{array}{c}\text { Achieving } \\
\text { the study's } \\
\text { objectives }\end{array}$ \\
\hline $\begin{array}{c}\text { Agreement ratio } \\
\text { Average of agreement ratio }\end{array}$ & $80 \%$ & $83 \%$ & $86 \%$ & $95 \%$ \\
\hline
\end{tabular}


previous five answers were graded hierarchically $(1,2,3,4,5)$, so that the high degree corresponds to the answer that is fully realized and the answer that is not fully realized takes the lowest degree from the answers of the managers of apparel factories.

The (Alpha Crow Nbach equation) was used to ensure the reliability of the tool on the study sample which is comprised of (10) managers in apparel factories. Table 2 shows the coefficient of reliability of the study tool.

It was found that the general reliability coefficient of the study axes was (0.594) for the total of the eighteen question paragraphs, while the reliability of the axes ranged between (0.299) as a minimum and (0.478) as a maximum, and this indicates that the questions of personal interview have a high degree of questions and its results can be relied on, according to Nunnally scale which adopts (0.070) as a minimum for reliability (Nunnally \& Bernstein, 1994) in statistical results.

\section{Procedures of Study Tool}

Based on the data collected from the personal interview with the managers of apparel factories, the analysis began by using different case study strategies, based on the methodology of Masocha and Fatoki's study (2018), where each apparel factory is considered as a single case to identify the challenges facing small and medium garment factories. Regarding the new commercial laws in Saudi Arabia, and in order to distinguish between the similarities and differences of factories in terms of the strategy they used to counter challenges, as well as their ability to apply economic sustainability, the method of qualitative data analysis was adopted because it provides a flexible and useful research tool that describes the data in rich details, by focusing more on identifying and describing implicit and explicit ideas in the answers.

Tables were created to analyze the responses of (10) managers to (18) questions that were answered and linked to previous studies; a method used in some studies that rely on personal interview as a tool for collection of information (Masocha \& Fatoki, 2018; Alakkad, 2018). Frequency tables were then generated to highlight the most important responses of the interviews, and show the variance of responses and the location of their intensity based on the qualitative data analysis procedures that were applied in Basaffar's study (2012).

These topics revolved around the theoretical framework and axes of study. The topics' interrelationship with research objectives and questions were studied to provide valuable information about these qualitative elements.

Table 2. Alpha Crow-Nbach coefficient to measure the reliability of the study tool.

\begin{tabular}{ccc}
\hline Axles & Number of phrases & Axle reliability coefficient \\
\hline The first axis (economic sustainability) & 11 & 0.478 \\
The second axis (economic challenges) & 7 & 0.299 \\
General consistency of interview questions & 18 & 0.594
\end{tabular}


These main and sub-themes were analyzed through cross-case analysis, to allow comparisons to be made between the ten cases of apparel factories in terms of presence and causes of economic challenges, the similarity between strategies taken by different factories to face economic challenges, and the differences in the application of elements of economic sustainability between apparel factories and the impact of this on their work plan.

\section{Discussion of Results}

Ten interviews were conducted with managers of apparel factories, in the period from September (2019) to September (2020). The interviewees had a good background about the community of small and medium apparel factory in the Kingdom (Table 3).

The demographic information presented in Table 3 shows that the respondents represented well factory managers from different cities in the field of apparel manufacturing, and of different age groups and educational backgrounds.

\section{Pillars of Discussion}

There were six pillars of discussion as follows:

The first pillar was related to the existence of economic challenges, and if these challenges are based on the research discussion.

The second pillar was a question about the existence of similarities between the challenges facing apparel factories. The interviewees in this section may add their experiences and observations, which can be a valuable contribution to reach a better understanding of the influencing factors.

The third is related to the impact of economic challenges on profit growth in apparel factories.

The fourth was related to the impact of economic sustainability on economic challenges facing apparel factories.

Table 3. Demographic information for the study participants.

\begin{tabular}{|c|c|c|c|c|}
\hline $\begin{array}{l}\text { Factory } \\
\text { code }\end{array}$ & Job title & Age & Qualification & $\begin{array}{c}\text { Years of } \\
\text { Experience }\end{array}$ \\
\hline *SS-1 & Operating manger & 26 - 30 years & University & $3-7$ years \\
\hline *SS-2 & General Director & 36 years and over & High School & More than 7 years \\
\hline${ }^{*}$ MS -1 & Director of Development & 36 years and over & University & More than 7 years \\
\hline${ }^{*} \mathrm{MS}-3$ & Operating manger & 26 - 30 years & University & $3-7$ years \\
\hline${ }^{*} \mathrm{MS}-4$ & General Director & 36 years and over & High School & $3-7$ years \\
\hline *SS-3 & General Director & 36 years and over & University & More than 7 years \\
\hline${ }^{*} \mathrm{MS}-2$ & Factory manager & 36 years and over & University & From 1 to 3 years \\
\hline${ }^{*} \mathrm{MS}-5$ & General Director & 36 years and over & University & $3-7$ years \\
\hline${ }^{*}$ MS -6 & Executive Director & 36 years and over & University & More than 7 years \\
\hline${ }^{*}$ MS-7 & Production Manager & 36 years and over & University & More than 7 years \\
\hline
\end{tabular}

${ }^{\star}$ MS: Medium size apparel factory; ${ }^{\star}$ SS: Small size apparel factory. 
The fifth pillar revolved around identifying the relationship between the solutions of the strategy applied by managers of apparel factories to face economic challenges, and the economic sustainability.

The sixth and last pillar revolves around the opinions of managers of apparel factory on the importance of such studies to boost the ability to face economic challenges and prepare for the application of economic sustainability.

\section{Summary of Results: Answering the Study's Questions}

The study aimed to examine the impact of economic sustainability of apparel factories on facing economic challenges. The study is likely to help solve the challenge related to financial pressures and tax liabilities. The study's questions were answered as follows:

First, the study's first question, which states: "What are the challenges facing the sample of apparel factories as a result of the new industrial and commercial regulations and laws?"

The answer to the question was obtained through answers of (4) questions aimed at identifying the economic challenges and when they began. These questions were based on a literature review of the actual economic situation in the Kingdom of Saudi Arabia and analysis of qualitative data of a sample of managers.

For example, the opinion of the Director General (MS-4), in which he states that "Tax laws and the labor office are the economic challenge facing the factory". His opinion confirms the impact of the new laws on the sample apparel factories, which are mentioned in Article 40 of the Ministry of Labor's regulations, and is consistent with the survey statistics on regulations and laws impeding growth in small and medium enterprises in the Kingdom (General Authority for Statistics, 2018).

Second, the answer to the second study question, which states: "What is the impact of the current economic climate of the Kingdom of Saudi Arabia on the strategies of apparel factories?"

The question was answered through answers of (3) sub-questions, which revolved around the solutions that contributed in overcoming the difficulties, crises, and the factory's economic stability, and how, from the managers' point of view, the factory's business plan changed. For example, the opinion of the General Manager (SS-3) in which he stated that "the plan has changed by shifting from a medium-sized factory to a small one".

This sector still faces difficult challenges to competitiveness and even sustainability. In addition, the apparel industry in Saudi Arabia represents the lowest percentage among other industrial facilities due to lack of exports and profits (Folkes, 2020).

In addition, it was found, through the qualitative analysis of the data, that the sample of the apparel factories had resorted to modifying the business plan and building an additional bridge to overcome the economic challenges and reach a 
state of stability. Among the solutions that helped stabilize the factory was, as an example, the opinion of a factory general manager (MS-3) in which he states that stability was obtained by "reducing the number of Saudi and non-Saudi employees in the factory by a small percentage, and add products to balance expenses and revenues." Therefore, one of the most effective solutions is to reduce work tasks so that there is balance between amount of labor and wages paid to employees.

Finally, the answer to the third question in the study which asks: "To which extent can apparel factories in the Kingdom of Saudi Arabia apply economic sustainability?"

The study found an answer to the question through answers of (11) key and sub-questions on elements of economic sustainability (productive efficiency of apparel factory, survival in the market and the financial plan of the factory).

First, the element of production efficiency in apparel factories. Through the answers, 10 managers highlighted the importance of providing in-house training for workers on operation of latest manufacturing techniques and operating costs reduction. Managers of apparel factories focused on reducing operating costs, as stated by one of the Operations Manager (MS-3) when he said, "We reduced the number of workers and relied on the latest cutting and sewing techniques to reduce dependence on manpower."

It is suggested that these solutions form an essential foundation for sustainable manufacturing. Technological development plays a major role in the process of shifting the economic system towards sustainability. These are exactly the elements that can be considered as the building blocks of economic sustainability (Hamidi, Widiyaanti, \& Sadalia, 2020).

The period of suspension of production due to failure of suppliers is indicators of measurement of production continuity in relation to suppliers (Roberts et al., 2018), and therefore we find that managers resort to reducing import costs endured by international suppliers, as in the case of factory (MS-2) which stated that "We import raw materials in bulk and at wholesale prices ... We rely on a core group of suppliers, a contingency group, and five-year long contracts at fixed prices."

Therefore, we find the role of reducing operating and supply costs, adopting the latest manufacturing techniques, and reducing as much as possible the number of workers the best approach in facing the economic challenges of the current study sample. This was confirmed by Hami, Muhamad and Ebrahim who stated that sustainable manufacturing practices such as reducing manufacturing costs have a positive impact on economic sustainability. Apparel factories were able to apply production efficiency and as a result, manufacturing operations continued.

Second, the element of staying in the market, by managing a budget dedicated to research and development of sales through the introduction of new products. Although no annual development expenditures are allocated, plant managers stated that expenditures on sales development are allocated only when needed. 
As stated by the general manager of factory (SS-2), "A budget is issued according to the case of the study that we carry out during the year." The study and development help small and medium enterprises to compete and remain sustainable at the market level (Garbie, 2016). This is what apparel factories need during these years that are merited by economic fluctuations. In the last annual report of the General Authority for Statistics (2018), it was stated that the percentage of clothing and textile factories that conduct study and development in the Kingdom is only $2.2 \%$, i.e. (464 out of 33,511 clothing and textile factories).

It was found that industrial cooperation between stakeholders is rejected in the sample of directors of apparel factories due to conflict of interest or competition, as the Executive Director (MS-6) mentioned, "Cooperation in terms of manufacturing with other factories is not available for competitive reasons. As for cooperation with designers or sectors interested in apparel, we have many of them." Although the general manager of a factory (SS-3) cooperated with another factory, yet this cooperation managed only to meet a big order without prejudice to the daily production rate of the apparel factory. This fact is neglected by some factory managers. Cooperation between industrial establishments compensates for the lack of certain resources in a particular factory due to their redistribution, ensuring the continuity of the positive economy of factories (Fomina et al., 2018), especially within the huge impact of COVID-19 on the global supply chain (Kaolawanich et al., 2020).

Previous studies confirm that survival in the market despite the economic fluctuations locally and internationally requires us to focus more on technology which is one of the main areas that are developing intensely. Internet is the way people conduct transactions, business and trade in modern work environments. With the internet, human activities in buying and selling transactions have now developed with the use of electronic media (Sholikhin \& Amijaya, 2019).

The Executive Director (MS-6) stated, "We have a website to display and sell the factory's products, pay with credit cards, and others." It is one of the methods used to reduce expenses, like the experience of a factory general manager (SS-3) which suggested to "shift from street exhibition to selling through the website". This is consistent with Miao and Tran's study (2018) about the role of electronic transactions in reducing expenses and economic pressure.

Through the results of qualitative data analysis, it was evident that the sample of apparel factories was not able to overcome markets' fluctuations, efforts were not exerted on research and development, and industrial cooperation was neglected as a factor in reducing the risks of halt of international supply operations, which means an imminent disruption of production operations.

Third, the factory's financial plan, which is the last element of economic sustainability to overcome economic challenges by developing a plan aimed at attracting local and international investors, and helping investors economically by introducing them to key stakeholders in the Kingdom in addition to access to capital, industrial land, commercial facilities, and support. However, $100 \%$ of the sample of managers of Saudi apparel factories did not have a financial plan for 
entry of investors. An example of which is the response of factory director-general (SS-3) when he stated: "So far, there is no plan for foreign investment due to the constant change in economic conditions."

It was found that $100 \%$ of the sample of Saudi apparel factories, in addition to factories with foreign investment, face difficulties in meeting government financial obligations. The director-general (SS-3) stated: "The difficulties lie in the fact that we are talking about foreign investment when the tax margin is $20 \%$ higher than domestic investment," whereas the Saudi Organization for Accountants and Certified Public Accountants stated that "taxes on foreign establishments are $20 \%$ on interest (SOCPA, 2020). This means that managers need to develop a financial plan for the factory to pay off government financial obligations without default.

Hence, we find that the sample of small and medium factories did not fully achieve the elements of economic sustainability, while the results of previous studies (Cantele \& Zardini, 2018; Malesios et al., 2018) confirm that the financial performance of small and medium enterprises appears more positive after applying the theory of sustainable economic.

Managers interviewed also referred to other issues related to labor laws and worker fees, which were supported in the literature. These issues are:

1) Employment of Saudis in clothing manufacturing as a factor to reduce operating costs. Interviewed managers emphasized that the presence of Saudi workers in manufacturing reduces costs, as non-Saudi workers incur fees and financial obligations that lead to economic challenges for the factory. However, lack of desire of female graduates of the fashion and textile dept. to work in clothing factories forces factory owners to rely on non-Saudi workers. According to the interviews, there is a need to focus on female university students, encourage them to work in fashion and textile factories, and remind them of the demands of the labor market.

2) The managers emphasized that they suffer from stagnation in profits since the imposition of added value on goods and services during (2016-2017 AD). They added that consumer purchasing behavior has a clear impact on sales of small and medium apparel factories. In addition to flooding the market with imported products, lower manufacturing costs of imported products help lower market prices and consequently consumer demand to buy them.

\section{Conclusion}

Through this study, we have presented the economic challenges facing small and medium apparel factories in the western region of the Kingdom of Saudi Arabia, the role of modern commercial and industrial laws, the recent strategy taken by apparel factory managers to survive and maintain the level of production efficiency, and the attempt to raise the sales growth index as before. In addition, this study presents financial and non-financial practices that ensure economic sustainability in a sample of apparel factories.

1) Answers on how to implement economic sustainability practices have 
shown that such practices do not lead to good economic performance due to the heavy financial obligations on owners of apparel factories.

2) The results indicate, based on a literature review and data of qualitative interview, that there is evidence of a positive relationship between the elements of economic sustainability and overcoming economic hardships.

3) The results of this study also show that a sample of successful factory managers in the Western region of the Kingdom has chosen the option of raising production efficiency from the list of elements of economic sustainability.

4) We concluded from the table of frequencies and qualitative analysis of the data that there is a lack of industrial cooperation between stakeholders to stay in the market, which in turn could have helped small and medium apparel factories to succeed in light of local and international economic changes and fluctuations, as well as market stability and flow of revenue to boost the Saudi economy.

5) The results of the analysis of qualitative data show a similarity between the economic challenges facing the sample of small and medium apparel factories, which means that the reasons for the emergence of these challenges are similar.

6) Failures of small and medium apparel factories negatively affect the Saudi local economy. Effective management to solve economic challenges in garment factories is one of the factors that lead to sustainability of a factory.

7) The results of the study show that the sample of small and medium apparel factories does not have the financial ability to pay tax obligations and achieve profits at the same time. These factories resort to reduction of costs of manufacturing and import. This choice is the best solution for stability and survival of the factory, which may increase the chance of factories' success and sustainability.

8) Reduction of operating costs in apparel factories, through use of energy-efficient modern technologies and minimizing the percentage of non-Saudi workers, is likely to continue as one of the solutions to face economic challenges.

\section{Recommendations}

This study is likely to have a role in many industrial fields not only because of the economic challenges facing small and medium apparel factories, but also because of the Kingdom's strategic transformation plan, Vision 2030, and its impact on many private and public sectors.

1) Investing in Saudi graduates (male and female) by enrolling them in specialized international training centers to receive adequate training in the fashion and textile industry.

2) Reducing operating costs which are necessary for obtaining government funding.

3) Attracting apparel and clothing factories to the importance of specialization which paves the way for industrial cooperation.

4) Planning to attract investors by working hard to improve quality and manufacturing standards, increase sales and stabilize financial performance, which will contribute to increasing capital and opening new horizons globally through 
the international investor.

5) Availing more funds to clothing and textile industries to enable them to lead economic diversification and encourage local production.

6) Forming an advisory committee in the Chambers of Commerce, to be specialized in fashion and textiles, to bridge potential gaps and find effective solutions to overcome economic difficulties and provide support for stability and survival.

7) From an economic perspective, encouraging relevant actors and stakeholders to be involved everywhere, especially with the huge impact of COVID-19 on the global supply chain network.

8) Renewing and rebuilding business plans in a strategic way. This would generate unparalleled growth in this sector, as it will be the source of the Kingdom's largest export and would contribute to the Saudi economy in a distinctive way.

9) Reviving the apparel and textile industry would logically produce a whole new set of related industries and facilitate the expansion of many activities of the services sector, and establishing production supplement factories.

\section{Conflicts of Interest}

The author declares no conflicts of interest regarding the publication of this paper.

\section{References}

Alakkad, J. A. M. (2018). Aligning the Appeal of Entrepreneurs to Investors: Why Is There a Need for an Optimal Entrepreneurship Training Module in the Kingdom of Saudi Arabia to Better Engage Entrepreneurs with Investors (pp. 2-295). Doctoral Dissertation, Durham: Durham University, Business School, United Kingdom. http://etheses.dur.ac.uk/12823

Alkhaldi, T., Cleeve, E., \& Brander-Brown, J. (2018). Formal Institutional Support for Early-Stage Entrepreneurs: Evidence from Saudi Arabia. International Conference on Innovation and Entrepreneurship, 903.

https://search.proquest.com/openview/347197d7c17c5fe4de5bd725399cff4d/1?pq-origs $\underline{\text { ite }=\text { gscholar } \& \mathrm{cbl}=4451211}$

Alkhateeb, T. T. Y., Mahmood, H., \& Sultan, Z. A. (2016). The Relationship between Exports and Economic Growth in Saudi Arabia. Asian Social Science, 12, 117. https://www.researchgate.net/profile/Tarek Alkhateeb/publication/299132475 The Re lation-

ship between Exports and Economic Growth in Saudi Arabia/links/5cc82f8392851 c8d220eaaf2/The-Relationship-between-Exports-and-Economic-Growth-in-Saudi-Ara bia.pdf https://doi.org/10.5539/ass.v12n4p117

Al-Mutawa, A. A. (2014). Marketing Problems and Practices in Small and Medium Industries: A Field Study in the City of Riyadh. King Saud University Journal-Administrative Sciences: King Saud University, 26, 129-143. https://cba.ksu.edu.sa/ar/Previous-numbers

Basaffar, A. A. (2012). Understanding the Entrepreneurial Potential of Female Saudi Ara- 
bian Family and Consumer Sciences Students and Businesswomen.| Graduate Theses and Dissertations, Ames, IA: Iowa State University.

https://lib.dr.iastate.edu/etd/12604

Blachut, J. (2019). Industrial Spaces in Small and Medium Cities in Southern Poland-The Selected Examples. IOP Conference Series: Materials Science and Engineering, 471, Article ID: 112082.

https://doi.org/10.1088/1757-899X/471/11/112082

https://iopscience.iop.org/article/10.1088/1757-899X/471/11/112082/meta

Brinkmann, S., \& Kvale, S. (2018). Doing Interviews (Vol. 2). London: SAGE Publications, Inc. https://uk.sagepub.com/en-gb/eur/doing-interviews/book244549 https://doi.org/10.4135/9781529716665

Bryman, A. (2016). Social Research Methods. Oxford: Oxford University Press.

Cantele, S., \& Zardini, A. (2018). Is Sustainability a Competitive Advantage for Small Businesses? An Empirical Analysis of Possible Mediators in the Sustainability-Financial Performance Relationship. Journal of Cleaner Production, 182, 166-176.

https://doi.org/10.1016/j.jclepro.2018.02.016

https://www.sciencedirect.com/science/article/abs/pii/S0959652618303202

Cooper, D. R., \& Schindler, P. S. (2014). Business Research Methods. Singapore: McGraw-Hill.; http://dln.jaipuria.ac.in:8080/jspui/bitstream/123456789/8296/1/Business\%20Research \%20Methods.pdf

Folkes, J. A. (2020). Strategies Small Business Leaders Implement for Outsourced IT Solutions for Business Sustainability (pp. 1-122). Minneapolis, MN: Walden University. https://scholarworks.waldenu.edu/dissertations/9360

Fomina, A., Berduygina, O., \& Shatsky, A. (2018). Industrial Cooperation and Its Influence on Sustainable Economic Growth. Entrepreneurship and Sustainability Issues, 5, 467-479. http://jssidoi.org/jesi/article/160 https://doi.org/10.9770/jesi.2018.5.3(4)

Garbie, I. (2016). Sustainability in Small and Medium-Sized Manufacturing Enterprises: An Empirical Study. The Journal of Engineering Research, 13, 42-57. https://journals.squ.edu.om https://doi.org/10.24200/tjer.vol13iss1pp42-57

Geissdoerfer, M., Savaget, P., Bocken, N. M., \& Hultink, E. J. (2017). The Circular Economy-A New Sustainability Paradigm? Journal of Cleaner Production, 143, 757-768. https://doi.org/10.1016/j.jclepro.2016.12.048

https://www.sciencedirect.com/science/article/abs/pii/S0959652616321023

General Authority for Statistics (2018). Industrial Activity Survey.

Hamidi, M., Widiyanti, M., \& Sadalia, I. (2020). Looking towards the Bigger Picture for Economic Sustainability of ASEAN Countries: Role of Consumption, Investment and Debt Growth. Journal of Security and Sustainability Issues, 10, 326-336. https://doi.org/10.9770/jssi.2020.10.Oct(25)

Kaolawanich, R., Oe, H., Yamaoka, Y., \& Chang, C. Y. (2020). A Discussion of a Luxury Apparel Brand Strategy in an Emerging Market: Conceptual Model with Network Perspectives. Journal of Social, Cultural and Political Studies, 4, 58-72. https://siasatjournal.com/index.php/siasat/article/view/57 https://doi.org/10.33258/siasat.v4i2.57

Masocha, R., \& Fatoki, O. (2018). The Impact of Coercive Pressures on Sustainability Practices of Small Businesses in South Africa. Sustainability, 10, 3032. https://doi.org/10.3390/su10093032

Nunnally, J. C., \& Bernstein, I. H. (1994). Psychometric Theory. 
Pickles, J., Plank, L., Staritz, C., \& Glasmeier, A. (2015). Trade Policy and Regionalisms in Global Clothing Production Networks. Cambridge Journal of Regions, Economy and Society, 8, 381-402. https://doi.org/10.1093/cjres/rsv022

Saudi Organization for Certified Public Accountants (SOCPA) (2020). Investment Incentives in the Kingdom of Saudi Arabia.

Sholikhin, M. Y., \& Amijaya, R. N. F. (2019). E-Commerce Based on the Law of Buying and Selling in Islam. The 2nd International Conference on Islamic Economics, Business, and Philanthropy (2nd ICIEBP), 1360-1370. https://doi.org/10.18502/kss.v3i13.4290

Virla, M. Q. (2010). Confiabilidad y coeficiente Alpha de Cronbach. Telos, 12, 248-252. https://www.redalyc.org/pdf/993/99315569010.pdf

Waked, B. (2016). Access to Finance by Saudi SMEs: Constraints and the Impact on Their Performance. Doctoral Dissertation, Footscray: Victoria University.? http://vuir.vu.edu.au/32466/1/WAKED\%20Bandar\%20-\%20Thesis.pdf 